\title{
O impacto da mentoria no desenvolvimento pessoal e profissional de diferentes turmas
}

\author{
The impact of mentoring on the personal and professional development of different classes
}

\author{
André Freitas Vargens ${ }^{1}$ \\ Milene Ortolan Wollmann' 1 \\ Daniel Akio Yamada ${ }^{1}$ \\ Carolina Guimaraes Herzog ${ }^{1}$ \\ Maria Eugenia Pinto ${ }^{1}$ \\ Alice Zelmanowicz ${ }^{1}$ \\ andrevargens@ufcspa.edu.br \\ milenew@ufcspa.edu.br \\ daniely@ufcspa.edu.br \\ carolinagh@ufcspa.edu.br \\ eugenia@ufcspa.edu.br \\ alicez@ufcspa.edu.br
}

\section{RESUMO}

Introdução: O programa de mentoria da Universidade Federal de Ciências da Saúde de Porto Alegre (UFCSPA) teve início em 2016, sendo ofertado de maneira eletiva. Seus objetivos são: orientação para o futuro profissional, apoio institucional formal, suporte emocional e compartilhamento de experiências durante a formação médica.

Relato de experiência: Os encontros foram conduzidos de modo não diretivo com temáticas predefinidas - escolhidas pelo mentor e pelos alunos. Os assuntos abordam tanto o desenvolvimento profissional do estudante quanto o pessoal, assim como a saúde mental dele. Vivência profissional, currículos formais e informais, sobrecarga e rendimento acadêmico foram alguns dos tópicos principais. Por meio dos relatos, foi possível perceber que os grupos reduzidos permitiram àqueles alunos que não se sentiam confortáveis para desenvolver algum assunto no currículo formal pudessem abrir-se e discutir temas relacionados ao curso.

Discussão: Notou-se uma mudança na postura de alguns alunos diante do curso e de momentos de lazer, valorizando tempo com a família, exercício físico e hobbies. Os encontros permitiram elucidar dúvidas sobre residência e carreira médica, assim como ajudaram os alunos a se reconectar com o curso.

Conclusão: O programa de mentoria da UFCSPA mostrou-se efetivo ao oportunizar reflexão sobre as vivências pessoais e o projeto profissional, e estimular a autonomia do pensamento crítico.

Palavras-chave: Mentores; Orientação Profissional; Saúde Mental; Educação a Distância.

\section{ABSTRACT}

Introduction: The Mentoring program of the Federal University of Health Sciences of Porto Alegre (UFCSPA) began in 2016, offered as an elective course. Its objectives are to provide orientation for the future professional, formal institutional support, emotional support and sharing of experiences during medical training.

Experience report: The meetings were conducted in a non-directive manner with predefined themes - chosen by the mentor and students. The subjects address both the professional and personal development of the student, as well as the individual's mental health. Professional experience, formal and informal curriculum, overload and academic performance were some of the main topics. The reports demonstrated that the small groups allowed students who did not feel comfortable talking about a subject in the formal curriculum to open up and discuss these subjects related to the course.

Discussion: A change was observed in the attitude of some students towards the course and free time, valuing time with the family, physical exercise and hobbies. The meetings allowed doubts to be clarified about residency and medical careers, as well as helping students to reconnect with the course.

Conclusion: The UFCSPA Mentoring Program proved to be effective in providing opportunities for reflection on personal experiences, professional projects and encouraging autonomous critical thinking.

Keywords: Mentors; Professional Orientation; Mental Health; Distance Learning.

\footnotetext{
${ }^{1}$ Universidade Federal de Ciências da Saúde de Porto Alegre, Porto Alegre, Rio Grande do Sul, Brasil.
}

Editora: Patrícia Lacerda Bellodi

Recebido em 03/03/21; Aceito em 26/04/21.

Avaliado pelo processo de double blind review. 


\section{INTRODUÇÃO}

O programa de mentoria da Universidade Federal de Ciências da Saúde de Porto Alegre (UFCSPA) teve início em 2016 como uma continuação do programa institucional de tutoria. Tendo em vista a necessidade dos discentes de uma orientação acerca de suas experiências acadêmicas e sobre seu futuro profissional dentro da carreira médica, esse programa foi instituído na universidade para dar direcionamento, apoio institucional formal e suporte emocional, e propiciar compartilhamento de experiências entre os mentores docentes e os mentorandos discentes. Essa disciplina eletiva é ofertada para os alunos a partir do segundo ano do curso, uma vez que, para os discentes do primeiro ano da graduação, existem outras disciplinas que destinam a orientá-los e introduzi-los no curso de Medicina e no ensino superior.

A Medicina é um curso que submete os discentes a grande desgaste emocional e físico, além de uma carga horária semanal apontada por muitos alunos como demasiada'. Conceição et al. ${ }^{2}$, no que diz respeito ao bem-estar do futuro médico, mostraram que, ao estimarem o nível de sofrimento psíquico dos acadêmicos, eles tinham taxa acima da média da população geral. Isso demonstra a necessidade de as universidades buscarem meios de reduzir esse sofrimento, visto que, em algum grau, ele é evitável. Na UFCSPA, os alunos já dispõem do Núcleo de Apoio Psicopedagógico (NAP) 3 que atende às necessidades essencialmente pedagógicas, como o planejamento dos horários de estudos e consultas regulares com psicólogos em casos de sofrimento psíquico. O NAP tem ainda como objetivos: combater discriminação de cunho racial, de gênero e sexual, e ampliar ações de promoção de saúde e prevenção de doenças em parceria com os estudantes. Além disso, o NAP é efetivo combate a qualquer forma de violência relacionada ao contexto universitário. Nesse cenário, a mentoria soma-se ao projeto de bem-estar dos alunos constituindo-se um facilitador para o desenvolvimento profissional - trata-se de um processo guiado por um médico.

A mentoria tem, portanto, entre seus objetivos, estimular a reflexão sobre as escolhas profissionais durante o curso; proporcionar um ambiente favorável para discussão aberta dos projetos pessoais e profissionais dos alunos, assim como as vivências experimentadas durante o curso; discutir com os alunos elementos para a melhoria da sua organização pessoal, estabelecendo estratégias para gerenciamento tanto do estresse quanto da ansiedade, desenvolvimento de resiliência e preparação profissional.

Os programas de mentoria são experiências recentes dentro dos currículos médicos brasileiros, cujo foco depende das experiências e dos formatos específicos de cada instituição ${ }^{4}$. Por conseguinte, este relato busca mostrar como a mentoria tem se desenvolvido na UFCSPA e analisar como a disciplina é conduzida, como os acadêmicos podem fazer parte dela e o diferente contexto de quem participou da disciplina durante a pandemia de severe acute respiratory syndrome coronavirus 2 (Sars-CoV-2), principalmente do ponto de vista dos estudantes. Por esses motivos, torna-se fundamental documentar a nossa experiência.

\section{RELATO DE EXPERIÊNCIA}

A mentoria no curso de Medicina da UFCSPA configurase como uma disciplina eletiva com carga horária de uma hora e 30 minutos semanais, disposta em um único encontro dos alunos com o mentor, docente do curso de Medicina. A disciplina acontece regularmente de forma presencial em salas do prédio principal do curso, no entanto, excepcionalmente em 2020, ocorreu pela plataforma Google Meet - recurso que tem sido ainda utilizado em 2021. Diante de algumas possibilidades, o mentorado pode escolher um dos horários abertos por cada mentor de acordo com a disponibilidade de vagas para as turmas ofertadas. Os grupos são constituídos pelo professor mentor e por aproximadamente 15 mentorados.

É importante ressaltar que, para um processo educativo se tornar efetivo, há muito mais do que um conteúdo a ser transmitido. A psicanálise destaca o papel importante da relação professor/aluno para que o aprendizado seja efetivo ${ }^{5}$, e para Freud a relação estabelecida entre os dois agentes da educação depende de imaginações e sentimentos que o discente projeta no docente ${ }^{6}$, processo denominado transferência. Assim, em um espaço que envolve significativo grau de avaliação dos desejos e anseios, faz-se interessante que os alunos possuam uma relação boa com os mentores. Para assegurar, portanto, um processo de transferência adequado, é benéfico que existam professores de diferentes departamentos, especialidades e personalidades como possibilidades de escolha para os discentes. Indubitavelmente, não há plena representatividade no quadro de mentores, considerando as infinitas possibilidades de combinação entre os três fatores expostos. Existem, porém, professores de ambos os sexos, de diferentes especialidades médicas e com personalidades diversas, o que assegura a possibilidade de o aluno optar pela turma por afinidade com o docente.

Ainda no que tange às estratégias utilizadas para construir um ambiente mais íntimo e que rompa com a rigidez e distância interpessoal da academia, os professores fizeram o uso de algumas estratégias. Uma das docentes, durante as aulas presenciais, realizava encontros com lanches no café da manhã. Outros grupos tiveram encontros específicos em horário de almoço para que nem todas as reuniões ficassem limitadas ao ambiente da sala de aula. Durante as 
aulas ministradas virtualmente, uma das mentoras utilizou ferramentas interativas para criar mapas mentais reflexivos com a sua turma. Em outro grupo, foi desenvolvida uma trilha sonora da mentoria, em que, a cada semana, dois alunos indicavam uma música para o grupo e justificavam o porquê da escolha, apontando sentimentos e compartilhando um pouco da sua cultura e de sua personalidade. Ao final do semestre, produziu-se uma playlist no YouTube que está disponível em https://www.youtube.com/playlist?list=PLPeVREi77fC2skGQxC wX_90o9712za-eg.

Sobre o formato dos encontros (quando presenciais), cabe destacar a utilização do espaço da sala por meio da disposição das cadeiras em círculos para não reproduzir o modelo diretivo de educação utilizado no restante das disciplinas formais do curso, por meio das carteiras alinhadas em direção ao professor que fica acima dos alunos em um tablado. Dessa maneira, o mentor estava sempre no mesmo nível dos alunos, integrando o grupo como um guia sem um possível papel de superioridade. Ribeiro ${ }^{5}$ ressalta que, no contexto acadêmico, é fácil estabelecer dualidades de sentimentos perante o educador, seja de amor e ódio, seja de censura e respeito. Ao passo que o mentor se coloca em uma posição acessível e próxima dos discentes, possibilitando que a transferência e contratransferência desencadeadas sejam positivas. No caso dos encontros realizados em 2020 e 2021, na modalidade on-line, a dinâmica de organização do espaço não foi relevante para as trocas propostas, o que gerou a necessidade do desenvolvimento de outras atividades para engajamento.

Quanto ao conteúdo desenvolvido nos encontros, ele pode ser agrupado em tópicos de desenvolvimento profissional e aqueles voltados para a saúde mental do estudante. Todavia, ambos os eixos foram transversalmente debatidos em todas as aulas, ainda que não como foco principal.

Os assuntos abordados são predefinidos, de modo que os alunos possam preparar-se para uma discussão mais proveitosa em um encontro não diretivo, de modo que haja participação ativa e protagonismo dos mentorados. Os cronogramas preveem algumas temáticas selecionadas pelo mentor, porém sempre com abertura para demandas espontâneas do grupo, para que os estudantes possam também elencar ideias de encontros com assuntos que consideram defasados no currículo formal ou anseios subjetivos quanto ao planejamento de carreira, por exemplo.

Nos temas de eixo do desenvolvimento profissional, os alunos alinharam-se bem aos temas pré-selecionados pelos docentes que abarcavam a vivência profissional do médico e as dificuldades de formulação e implementação de um currículo que abrangesse o desenvolvimento das habilidades e competências profissionais necessárias ao médico generalista. Podemos citar entre os temas: discussões sobre a relação médico-paciente7; o local de trabalho médico; as diversas possibilidades de carreiras a se seguir, desde a rotina de consultório clínico até a rotina de médico cirurgião, médicopesquisador, médico do Exército e, inclusive, do profissional em novas áreas emergentes, como medicina integrativa; os modelos de remuneração; o futuro do mercado de trabalho e como se inserir nele após a graduação; a rotina de um interno e de um residente; além de questões éticas com as quais o médico tem de lidar no seu cotidiano profissional.

O espaço para debate desses assuntos no grupo trouxe à tona dúvidas que muitos alunos não se sentiam à vontade de explorar na abordagem do currículo formal em disciplinas regulares do curso. Entre os tópicos abordados, destacam-se a possibilidade de conciliar a escolha da especialidade com o estilo de vida, não se especializar e os modelos das jornadas de trabalho pretendidas pelos futuros profissionais. $E$ desses tópicos derivaram alguns outros aspectos profissionais: "É uma especialidade que implica em muitos plantões?", "São muitos anos até o final da especialização através de residências?" e "Precisarei trabalhar em muitos locais distintos?". Também surgiram dúvidas de como construir um currículo que contemple os desejos dos alunos, mas que também os projete para a carreira almejada. Por meio desses encontros, foi possível debater a existência e pensar acerca de um currículo paralelo que não sobrecarregue o discente, mas que o prepare para o mercado de trabalho e para o mundo científico que o permeará. Ainda no tema da construção de carreira, dúvidas referentes aos caminhos para tornar-se um gestor em saúde ou pesquisador, por exemplo, foram acolhidas com mais atenção, visto que as informações para essas áreas em particular são menos frequentes nas aulas regulares.

As temáticas referentes à saúde mental proporcionaram aulas mais intensas por vezes, em função da potência das emoções afloradas dos discentes. A depreciação psíquica, como estresse, ansiedade e fadiga, e a pressão de um ambiente competitivo foram relatadas por muitos - e muitas vezes como fatores que limitam o rendimento acadêmico e geram ciclos que se retroalimentam intensificando o sofrimento psíquico.

Destaca-se, entre os relatos, a angústia psicológica, situação documentada como prevalente entre acadêmicos de Medicina no Brasil ${ }^{2}$. De forma quase unânime, os alunos relatam decepções ao ingressarem no curso - empolgados e repletos de anseios positivos - e gradualmente notarem uma depressão no humor com a abrupta mudança de rotina e sobrecarga de conteúdos a serem absorvidos. $\mathrm{O}$ excesso de conhecimento a aprender, a grande quantidade de atividades extracurriculares - estágios, ligas acadêmicas e iniciações científicas, por exemplo -, a pressão das responsabilidades assumidas e a falta de tempo para dispor de lazer e praticar atividades físicas 
tornam-se um emaranhado cíclico e vicioso que prende muitos dos alunos. A administração do tempo de forma saudável, sem que a graduação ocupe todos os turnos, inclusive durante finais de semana, foi uma dificuldade frequente no grupo. Além disso, alguns discentes apontaram, ao longo dos encontros, o sentimento de competitividade constante entre os colegas, o que desgasta muito as relações interpessoais cotidianas.

É interessante notar que muitas das angústias expostas transversalmente ao longo do tempo encontravam ouvintes empáticos que compreendiam a dor dos colegas. Mais que isso, os docentes por vezes relataram que estiveram em situação semelhante, e assim foi possível, dentro dos limites cabíveis a nós como colegas de grupo - e não psicoterapeutas -, trocar conselhos de como assegurar espaço na agenda para lazer e esportes, e meios para não deixar que a pressão por produtividade engolisse a subjetividade dos discentes. Um dos grupos vivenciou um debate absolutamente relevante sobre os riscos de priorizar a produtividade irrestrita em detrimento dos anos de juventude que deveriam coexistir com a graduação de forma salutar. Notar, por exemplo, que as boas evidências em educação defendem o espaço para o lazer e descanso foi apontado como uma forma de não cair nas armadilhas do meio competitivo e repensar a relação com o curso e que espaço ele ocupa em nossa vida.

\section{DISCUSSÃO}

Após a avaliação do impacto dos encontros de mentoria, considerou-se positiva a mudança de postura de muitos alunos diante do curso, em diferentes aspectos. Os debates referentes à retomada das atividades de lazer trouxeram à tona muito do aspecto emocional dos alunos. Foram muitos os relatos de promoção de saúde física e mental, como o desejo de tocar um instrumento musical, dedicar mais tempo à escrita de poesias, passar mais tempo com os animais de estimação e com amigos e família fora do curso. Muitos hobbies perdidos pela falta de tempo - ou pelo manejo inadequado deste - entraram no planejamento dos discentes, uma vez que a percepção da importância deles no que tange à saúde global os estimulou a realizar essa mudança comportamental ao longo da disciplina ${ }^{8}$.

Todavia, essa incorporação de novos hábitos proveniente da reflexão acerca da necessidade de lazer não foi fácil ou realidade para todos os alunos. Mesmo com a implementação do programa de mentoria, a mentalidade dos estudantes é muito focada em um sistema de demandas por eficiência e produtividade próprias do modelo de ensino promovido pelas faculdades de Medicina9 ${ }^{9}$ Isso se dá pela grande carga horária de disciplinas e de estudos extraclasse exigidos do estudante, desenvolvendo um ambiente em que o autocuidado sempre ocupe um segundo plano quando se trata de prioridades para o discente, ou seja, o bem-estar dele passa a ser negligenciado

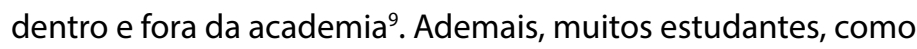
era de se esperar, demonstraram resistência em abrir espaço tanto para a mentoria quanto para atividades extracurriculares não acadêmicas ${ }^{10}$, o que estava alinhado à lógica competitiva inerente ao curso. Alguns discentes, por vezes, consideravam a atividade reflexiva "perda de tempo", visto que não agregaria nada ao currículo e nem representaria um diferencial direto no desempenho em processos seletivos.

Abordaram-se também outros aspectos pessoais da vida universitária. Estratégias de como lidar com os vários aspectos de mudança de vida foram trazidas regularmente. Os discentes indicaram a rotina e o ciclo de convívio impostos pelo curso como um fator desafiador a ser enfrentado paralelamente aos estudos. Alunos oriundos de outras cidades e estados pontuaram dificuldades em morar longe da família, em manejar a solidão em uma cidade desconhecida e em lidar com a sensação de estar perdendo momentos perto de entes e amigos queridos. Nesses encontros, trocas puderam ser feitas sobre a importância de consolidar uma nova rede de apoio ao entrar na universidade, além de pensar formas de manter contato com aqueles que já faziam parte da vida de cada um. Esse processo é saudável, visto que, dentro da cultura médica, percebe-se grande dificuldade do médico e do acadêmico de assumir papel de paciente e mostrar as fragilidades inerentes à natureza humana em situações de estresse e grande desgaste, seja emocional, seja físico ${ }^{11}$. Isso ocorre porque, desde a entrada na universidade, é exigido do futuro profissional que ele assuma um papel de omnisciente e onipotente ${ }^{11}$ perante a sociedade, ou seja, manter o estereótipo de que médico é um indivíduo "divino", não se permitindo falhas.

A resiliência, como potência subjetiva, pôde ser utilizada para que o grupo pudesse ver sob outra ótica as perdas de um estilo de vida que se esvai em favor da realização de desejos pessoais - cursar Medicina. Alguns grupos foram estimulados a escrever sobre outros momentos de adaptação para que pudessem compreender a beleza e o significado do processo pelo qual passavam e resgatar os ideais que os motivaram a ingressar no curso. Outros grupos tiveram a possibilidade de contar sua história e trajetória de vida em momentos de conversa informal, o que permitiu que emoções florescessem e compartilhassem risos e lágrimas que acompanham a história de cada mentorado.

Os desejos que motivaram a escolher o curso também foram bastante pautados. Ademais, os encontros com profissionais médicos para elucidar dúvidas sobre residência e carreira médica, de modo geral, despertaram nos alunos o desejo de se reconectar com o curso de forma mais salutar. Por meio desses relatos, foram estimulados a refletir e reavaliar a maneira como pensam sobre o caminho a ser percorrido ao longo da graduação, não como fardo de produtividade 
para olhares de outros, mas sim como um desejo pessoal em construção. Além do movimento de retomarem as atividades de prazer e de saúde (prática de atividades físicas, hobbies e cuidado com a alimentação), alguns alunos expressaram que, ao longo do semestre, sentiram-se mais conectados com a felicidade que sentiram quando calouros. Nas palavras de uma das alunas, a mentoria fez muitos do grupo retomarem o "brilhos nos olhos" pela carreira médica.

Avaliar o desenvolvimento do programa de mentoria durante o período de distanciamento social em decorrência da pandemia da Sars-CoV-2 - implica olhar para um cenário imprevisto e totalmente virtual. Quanto ao espaço de acolhimento um pouco mais leve e próximo referido por alunos das turmas de 2019, houve divergências na avaliação das turmas de 2020. Alguns alunos relataram que ficaram mais confortáveis de expor suas opiniões e subjetividades nos encontros on-line, por estarem em suas casas - confortáveis e livres do rigor inerente à universidade. Além disso, evidenciouse nesses relatos a sensação de satisfação por ter um ambiente acadêmico que promovesse o compartilhamento das angústias despertadas e da sobrecarga emocional pelo modelo excepcional de aulas no formato on-line. Contudo, alguns alunos mencionaram que ficavam mais intimidados em se expor virtualmente e sentiam que a distância do ensino remoto impossibilitou a plena conexão com o espaço.

É evidente que pensar a dificuldade de participação nas aulas nos coloca o questionamento de se toda a responsabilidade seria do modelo remoto, visto que alguns alunos disseram que o medo da retaliação do professor ou institucional gera desconforto para falar de incômodos relacionados à faculdade ${ }^{12}$. Um discente trouxe a dificuldade de se confiar em alguém cuja relação se constituiu de forma virtual, ilustrando, por exemplo, o impasse no estabelecimento de uma transferência adequada no modelo remoto, especificamente. Ademais, ainda no que tange às interações no modelo remoto, não foram raros os alunos que não abriam a câmera ou não falavam muito por dividirem o espaço físico com outras pessoas: "Meu pai está trabalhando aqui do lado", "Meu cachorro está latindo muito" e "Estou assistindo à aula da rua, estava no médico". Podemos pensar numa "dupla barreira", pois, além de romperem o silêncio e exporem seus sentimentos diante da turma, os alunos ocasionalmente enfrentavam a falta de privacidade.

O modelo virtual teve também o potencial de silenciar alguns alunos quando parte significativa da turma já se conhecia previamente. Docentes de turmas diferentes notaram o efeito de "panelinhas virtuais"13. O fato é comum na nossa vida cotidiana - e presencial: chegar a um grupo já formado implica a conquista de um espaço. Nesse sentido, nas turmas nas quais os alunos tinham menos contato fora do grupo de mentoria, a participação pareceu mais democrática na percepção de alguns colegas. Embora também existam benefícios no grupo previamente harmônico, percebemos que os alunos levaram menos tempo para interagir com o mentor nas aulas.

Outro relato interessante vem também daqueles que não participaram da mentoria. Muitos alunos disseram que a sobrecarga de atividades promovidas durante o ensino remoto pelas disciplinas regulares do curso pesou para que optassem por não ingressar no programa durante o período de matrículas. Os alunos que participaram em 2020 também apontaram no debate que se sentiam esgotados pelo ensino a distância e, dessa forma, não podiam entregar-se plenamente ao espaço construído pelo grupo com os docentes.

Uma das grandes barreiras impostas pelo ensino no modelo virtual foi a acessibilidade justamente ao ambiente on-line. Dificuldades de acesso foram relatadas, ainda que de forma pontual, como falhas de conexão ou internet instável por vezes. Entraves desse tipo acabam criando desgastes no engajamento dos alunos nas discussões desenvolvidas nos encontros. Além disso, é importante considerar que aqueles com acesso precário à internet tiveram um empecilho extra ao decidirem matricular-se ou não no programa de mentoria. Por parte dos mentores, surgiram comentários acerca da falta de interatividade que é conduzir grupos de alunos que não mantêm as câmeras ligadas ao longo da aula.

Contudo, o ensino remoto não foi a única limitação do processo desenvolvido na mentoria. Em ambos os anos, 2019 e 2020, as turmas expuseram alguns pontos, como a limitação do tempo de debate por uma hora e 30 minutos de duração dos encontros, ante o grande volume de dúvidas inerentes aos temas trabalhados. É possível encarar essa questão como natural e pertencente a todo processo no qual há aprendizado - o saber gera sempre novos questionamentos. Todavia, podemos considerar a hipótese de consolidar programas de mentoria ao longo de todos os anos da graduação. É evidente que essa questão requer debates mais aprofundados sobre o efetivo benefício e a viabilidade de estender o programa pelo currículo.

Por fim, alguns alunos relataram que demoraram algum tempo para sentir-se mais livres e confortáveis com os colegas de grupo e o mentor. Isso acarretou perdas individuais, na medida em que alguns alunos não participaram plenamente de alguns encontros, e, também, perdas coletivas, uma vez que o silêncio de um membro do grupo significa menos troca de ideias para o debate ali proposto.

\section{CONCLUSÃO}

O programa de mentoria da UFCSPA, apesar de ainda apresentar pontos que podem ser aperfeiçoados, mostrou-se efetivo em seu objetivo geral de "oportunizar a reflexão sobre 
vivências pessoais durante o curso de medicina, acompanhar o projeto profissional e desenvolver autonomia e pensamento

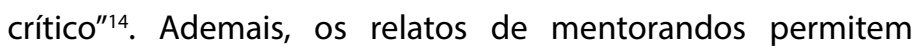
considerar a hipótese de que os alunos saem da mentoria com um olhar mais crítico acerca da visão fatalista de que a carreira médica implica sofrimento. Os alunos, por conseguinte, referem que se sentem mais estimulados a guiar a própria trajetória na graduação de forma salutar e mais proveitosa.

\section{CONTRIBUIÇÃO DOS AUTORES}

André Freitas Vargens e Milene Ortolan Wollmann participaram da organização de ideias para estruturar o relato e da escrita e revisão final do texto. Daniel Akio Yamada participou da escrita do texto introdutório. Carolina Guimaraes Herzog participou da elaboração do relato. Maria Eugenia Pinto e Alice Zelmanowicz forneceram contribuições importantes sobre o ponto de vista docente e foram responsáveis pela revisão final do texto.

\section{CONFLITO DE INTERESSES}

Declaramos não haver conflito de interesses.

\section{FINANCIAMENTO}

Declaramos não haver financiamento.

\section{REFERÊNCIAS}

1. Benevides-Pereira AM, Gonçalves MB. Transtornos emocionais e a formação em Medicina: um estudo longitudinal. Rev Bras Educ Med. 2009;33(1):10-23.

2. Conceição LS, Batista CB, Dâmaso JGB, Pereira BS, Carniele RC, Pereira GS. Saúde mental dos estudantes de medicina brasileiros: uma revisão sistemática da literatura. Avaliação (Campinas). 2019;24(3):785-802.
3. Núcleo de Apoio Psicopedagógico. Plano de Desenvolvimento Institucional - PDI: 2020-2029. Universidade Federal de Ciências da Saúde de Porto Alegre; 2019 [acesso em 23 fev 2021]. Disponível em: https://www.ufcspa. edu.br/documentos/institucional/ufcspa-pdi-2020-2029.pdf.

4. Ribeiro MM, Martins A, Fidelis GT, Goulart GC, Molinari LC, Tavares EC. Tutoria em escola médica: avaliação por discentes após seu término e ao final do curso. Rev Bras Educ Med. 2013;37(4):509-14.

5. Ribeiro MP. Contribuição da psicanálise para a educação: a transferência na relação professor/aluno. Psicol Educ. 2016 [acesso em 28 mar 2021]. Disponível em: https://revistas.pucsp.br/index.php/psicoeduca/article/view/26701.

6. Freud S. Algumas reflexões sobre a psicologia escolar. Totem e tabu e outros trabalhos (1913-1914). Edição standard brasileira das obras psicológicas completas de Sigmund Freud. Rio de Janeiro: Imago; 1996. v. XIII, p. 245-50.

7. Trindade LM, Vieira MJ.O aluno de medicina e estratégias de enfrentamento no atendimento ao paciente. Rev Bras Educ Med. 2013;37(2):167-77.

8. Wolf TM, Kissling GE. Changes in life-style characteristics, health, and mood of freshman medical students. J Med Educ. 1984;59(10):806-14 [acesso em 29 mar 2021]. Disponível em: https://pubmed.ncbi.nlm.nih.gov/6481777/.

9. Lauxen DB. Intervenções institucionais para promoção do bem-estar dos estudantes de medicina [trabalho de conclusão de curso]. Florianópolis: Universidade Federal de Santa Catarina; 2020.

10. Grant A, Kinnersley P, Metcalf E, Pill R, Houston H. Students' views of reflective learning techniques: an efficacy study at a UK medical school. Med Educ. 2006;40(4):379-88 [acesso em 28 mar 2021]. Disponível em: https://pubmed.ncbi.nlm.nih.gov/16573675/.

11. Prata CA. O Programa de Mentoria Acadêmica como apoio ao estudante no curso de medicina da FACISB. Rev Manuscripta Medica. 2020;3:74-80.

12. Straus ES, Johnson MO, Marques C, Feldmam MD. Characteristic of successful and failed mentoring relationships: a qualitative study across two academic health centers. Rev Acad Med. 2013;88(1):82-9.

13. Mercado PL. Dificuldades na educação a distância online. CONGRESSO INTERNACIONAL DE EDUCAÇÃO A DISTÂNCIA, 13., 2-5 set. 2007, Abed, Curitiba [acesso em 28 maio 2021]. Disponível em: http://www.abed.org. br/congresso2007/tc/55200761718PM.pdf.

14. Universidade Federal de Ciências da Saúde de Porto Alegre. Plano de ensino - mentoria 2018. UFCSPA; 2018 [acesso em 24 fev 2021]. Disponível em https://www.ufcspa.edu.br/documentos/atividadescomplementares/planos-2019-2/mentoria.pdf. 